\title{
Alas, there are no shortcuts to the complexities of the economy
}

Marisol Rodríguez, ${ }^{1}$ Beatriz González López-Valcárcel ${ }^{2}$

\begin{abstract}
'If the Lord Almighty had consulted me before embarking upon Creation, I should have recommended something simpler'. ${ }^{1}$ Alfonso X 'The Wise' (1221-1284),

Spanish King of Castile and León.
\end{abstract}

In their article, Mackenbach et al try to translate health into monetary figures in order to back up with economic arguments their advocacy of intersectoral actions to tackle health inequalities. The reduction of health inequalities by way of improving the health of the less educated-their levelling up approach-would lead to economic gains through its impact on labour participation, labour income, GDP, social security benefits, healthcare costs and total welfare. Taken at face value, the results are forceful: health inequalities across Europe-25 are responsible for more than 700000 deaths per year, 33.5 million prevalent cases of illhealth, $20 \%$ of the total healthcare costs, $15 \%$ of the total costs of social security benefits and welfare losses that amount to 9.4\% of the GDP (almost $€ 1000$ billion per year).

Simple numbers are attractive when they seem to capture complex phenomena in just a few quantitative magnitudes that are appealing to the mass media because they can easily hit the headlines. The implicit assumption behind the authors' calculations is that economic variables are independent and that there are no crosseffects beyond the most obvious direct effects. However, as early as in 1874 French mathematical economist Léon Walras ${ }^{3}$ recognised as the founder of the theory of general equilibrium in economics-had called attention to the fact that in a market economy the prices and the production of all goods and services (including the price of money) are interrelated. Therefore,

\footnotetext{
1Department of Economic Policy, Facultad de Economía y Empresa, University of Barcelona, Barcelona, Spain; ${ }^{2}$ Department of Quantitative Methods in Economy and Management, University of Las Palmas de Gran Canaria, Las Palmas de Gran Canaria, Spain

Correspondence to Professor Marisol Rodríguez, Department of Economic Policy, Facultad de Economía y Empresa, University of Barcelona, Avda. Diagonal 690, Barcelona 08034, Spain; marisol.rodriguez@ub.edu
}

a change in the price of one good is going to affect all other prices in the economy. His analysis was later extended by Kenneth Arrow and Gerard Debreu. ${ }^{4}$ What this means is that, if one wants to be thorough, one variable cannot be changed without tracking changes in all other variables. Given the insurmountable empirical difficulty in performing such an exercise for any particular national economy, general equilibrium theory is an abstraction rather than an empirical procedure. But to all economic analysts and in all macroeconometric models it is clear that an exogenous shock in any macroeconomic variable will have multiplying effects on the rest of the system's variables.

Let us mention here just three examples of the type of cross-effects that would have to be taken into account in the study we are discussing from a general equilibrium-or just a system's- perspective.

First, under the authors' levelling up approach, the self-assessed health, the mortality and the utilisation of health services of the $50 \%$ more educated segment of the population are attributed to the $50 \%$ less educated segment, but clearly one would also have to acknowledge and compute changes in their jobs, salaries, incomes, homes, health-related lifestyles, etc.

Second, the authors claim that the reduction of health inequalities would improve what they call labour productivity. (The authors loosely represent labour productivity by labour market participation, number of hours worked and hourly income. Actually, economists' definition of labour productivity is that it is the ratio of output to labour input, which may increase with an improvement in education, not with a reduction in health inequalities.) But one has to take into account that enhanced labour productivity would increase GDP, which in turn could affect total health expenditures, given the well-known macroeconomic elasticity of health expenditures to GDP.

Finally, the assumption that the levelling up scenario would decrease physician visits by $16 \%$ and hospital nights by $22 \%$ takes for granted that the supply of healthcare would not respond to this change in demand. However, just a little faith in the existence of supplier-induced demand $d^{5}$ is enough to warn us that this may not happen. Very likely, suppliers would find ways to encourage consumption of more healthcare services to offset that decline in demand. And in the event of a decrease in the utilisation of healthcare services actually happening, the authors should then try to estimate what the negative effect of that $20 \%$ reduction of healthcare costs would be on aggregate employment and the GDP.

In sum, the problem is that while the economic puzzle is very complex and all pieces interact, the study considers only univariate changes taken one-by-one in a fragmented fashion. Even if the authors do not assume the 'upward levelling' hypothesis as a policy objective that could be realistically achieved in Europe, their plain calculations to estimate the macroeconomic effects of the equalitarian scenario are in sharp contrast with the increasingly sophisticated methods-and social experiments-proposed in the literature $^{6}$ to estimate the effects of policy interventions with counterfactuals (What would happen if...?).

Another issue critics might raise is that the authors do not confront their 'upward levelling' hypothesis with other alternatives. Desirably, the sensitivity analysis could have been extended to cover other-perhaps more feasible-scenarios. One fruitful approach, following Tang et al,,$^{7}$ is to distinguish between avoidable and unavoidable inequalities. Under this approach, the assumption would be that inequalities in every European country could be reduced to the level of the better off country in the health indicator chosen. Still another alternative the authors could have considered is that every country should reduce the magnitude of inequality by a certain fixed percentage, which would leave room for differences among countries-given their ample heterogeneity-while still requiring a reduction in all of them.

The heterogeneity of the countries and the lack of data for many of them is a final consideration worth mentioning. The assumptions to overcome both aspects are too hasty and poorly explained. Altogether, the results come from a cascade of calculations and rough estimates based on suppositions and modelling artefacts that may amplify errors. Therefore, although we share the authors' interest in reinforcing the arguments that support policies to reduce health inequalities, we feel the frailty of and the lack of sound 
economic support for their figures may invalidate their usefulness for policy purposes.

\section{Competing interests None.}

Provenance and peer review Commissioned; not externally peer reviewed.

Published Online First 17 February 2011

J Epidemiol Community Health 2011:65:389-390. doi:10.1136/jech.2010.130005

\section{REFERENCES}

1. Andrews R, Biggs M, Seidel M. Columbia World of Quotations. New York: Columbia University Press, 1996. http://quotes.dictionary.com (accessed 9 Feb 2011).

2. Mackenbach JP, Meerding WJ, Kunst AE. Economic costs of health inequalities in the European Union. $J$ Epidemiol Community Health 2011;65:412-19.

3. Walras L. Éléments d'économie politique pure, ou théorie de la richesse sociale. 1874. (Elements of Pure Economics, or the Theory of Social Wealth. Transl by W Jaffé. Homewood, IL: Richard D. Irwin; London: George Allen and Unwin Ltd, 1954).
4. Arrow KJ, Debreu G. Existence of a competitive equilibrium for a competitive economy. Econometrica 1954;22:265-90.

5. Fuchs V. The supply of surgeons and the demand for operations. J Hum Resour 1978;13:35-56.

6. Khandker SR, Koolwal GB, Samad HA. Handbook on Impact Evaluation: Quantitative Methods and Practices. Washington, DC: World Bank, 2010.

7. Tang KK, Chin JTC, Prasada Rao DS. Avoidable mortality risks and measurement of wellbeing and inequality. J Health Econ 2008;27:624-41.

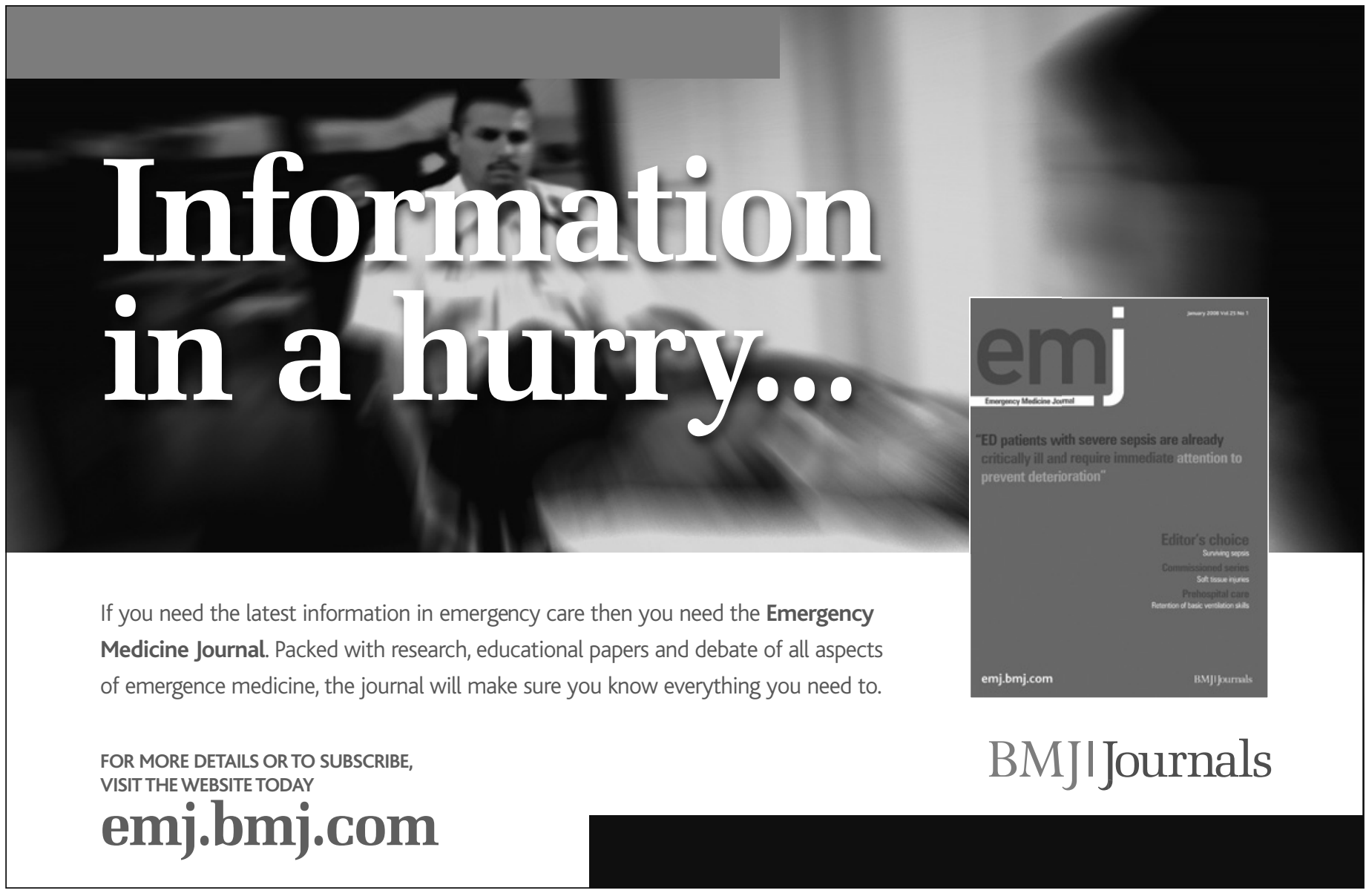

